\title{
Management of a rare case of extra hepatic portal vein obstruction with temporomandibular joint ankylosis and review of literature
}

\author{
Kailash Chand Kurdia ${ }^{1}$, Ambuj Aggarwal ${ }^{1}$, Cherring Tandup ${ }^{1}$, \\ Divya Dahiya ${ }^{1}$, Subrata Podder ${ }^{2}$, and Arunanshu Behera ${ }^{1}$ \\ Departments of ${ }^{1}$ General Surgery, ${ }^{2}$ Anesthesia and Critical Care, \\ Post Graduate Institute of Medical Education and Research, Chandigarh, India
}

\begin{abstract}
Extrahepatic portal venous obstruction (EHPVO) and temporomandibular joint (TMJ) ankylosisis are significant problems in Asian countries. Both EHPVO and bilateral TMJ ankylosis may have rare association due to protein $\mathrm{C}$ and $S$ deficiency which may cause hypercoagulability as well as reduced fibrinolytic activity. Ankylosis arising in early childhood is associated with facial asymmetry, feeding difficulty and speech development alterations. It is also associated with great challenges of endoscopic management in extra hepatic portal vein obstruction (EHPVO) with variceal bleed as well as air way management during surgical management and post-operative recovery. Recently a case series had shown association of TMJ ankylosis with EHPVO due to protein $\mathrm{C}$ deficiency which might be an etiological factor for both EHPVO as well as TMJ ankylosis. This case report documents a case of 14 year young girl who had TMJ ankylosis due to ear infection and EHPVO with esophageal varices had multiple episodes of upper GI bleed with mild deficiency of protein $\mathrm{C}$ and $\mathrm{S}$, successfully managed with proximal splenorenal shunt to prevent further episodes of upper GI bleed, as endoscopic management is not feasible due to TMJ ankylosis. (Ann Hepatobiliary Pancreat Surg 2021;25:283-286)
\end{abstract}

Key Words: EHPVO; Variceal bleed; TMJ ankylosis; Proximal splenorenal shunt

\section{INTRODUCTION}

Extrahepatic portal venous obstruction (EHPVO) is the most common cause of portal hypertension and upper gastrointestinal (UGI) bleed in children which is most commonly caused by thrombosis of the portal venous system. In about $50 \%$ cases of portal vein thrombosis, the cause remains unknown while rest of the patients have predisposing factors like hypercoagulable conditions (myeloproliferative disorders, inherited deficiencies of natural anticoagulant such as antithrombin III, protein $\mathrm{C}$ and protein $\mathrm{S}$, activated protein $\mathrm{C}$ resistance (APCR), or prothrombin gene (G20210A) mutation). ${ }^{1,2}$

Both EHPVO and TMJ ankylosis are significant health problems in developing countries, usually seen in poor socioeconomic patients. ${ }^{2,3}$ Recently association of EHPVO and temporomandibular joint (TMJ) ankylosis has also been reported. Sahoo et al. ${ }^{4}$ for the first time reported an eightyear old boy with diagnosis of TMJ ankylosis with EHPVO who presented with recurrent episodes of haematemesis and melena. Endoscopic management was not possible due to lack of adequate mouth opening and hence underwent release of right TMJ ankylosis with inter-positional, arthroplasty before further management. Since then only five cases have been reported in literature till date. We hereby present a case of 14-year young girl presenting with TMJ ankylosis with EHPVO with recurrent episodes of upper GI bleed.

\section{CASE}

Our index case is a 14-year old girl having a history of recurrent bilateral ear infection since the age of 1 year for which she used to receive only symptomatic treatment

Received: August 20, 2020; Revised: September 16, 2020; Accepted: September 20, 2020

Corresponding author: Arunanshu Behera

Department of General Surgery, Post Graduate Institute of Medical Education and Research, Chandigarh 160012, India Tel: +91-172-2756638, Fax: +91-172-2744401/2745078, E-mail: abe190859@yahoo.com

Copyright (C) 2021 by The Korean Association of Hepato-Biliary-Pancreatic Surgery

This is an Open Access article distributed under the terms of the Creative Commons Attribution Non-Commercial License (http://creativecommons.org/ censes/by-nc/4.0) which permits unrestricted non-commercial use, distribution, and reproduction in any medium, provided the original work is properly cited. Annals of Hepato-Biliary-Pancreatic Surgery - pISSN: 2508-5778 - elSSN: 2508-5859 
along with gradual restriction of mouth opening. On evaluation, she was found to have bilateral TMJ ankylosis. She also gave a history of recurrent episodes of hematemesis and melena for 6 years of age which was managed conservatively with blood transfusions but could not be evaluated further due to restricted mouth opening. The last bleeding episode occurred 2 years back, when she was referred to our center. Here, she was initially evaluated in department of Pediatric Gastroenterology where the diagnosis was established as EHPVO.

On examination, she was found to have mild pallor without any icterus but there was minimal mouth opening with micrognathia (Fig. 1). Abdominal examination revealed moderate splenomegaly. Her blood investigations showed features of hypersplenism (Hemoglobin $9.9 \mathrm{mg} / \mathrm{dl}$, Total Leukocyte Count $2100 / \mathrm{mm}^{3}$, platelets $61000 / \mathrm{mm}^{3}$ ), liver function test and kidney function test were normal. Procoagulant workup showed mildly decreased levels of protein C [68.3 IU/dl, (normal range 72.3-155.1)] and protein $\mathrm{S}$ [57.3 U/dl, (normal range 61.4-130.7)], rest (international normalized ratio, antithrombin III) were normal. Ultrasound showed normal liver. However, on performing Doppler ultrasonography portal vein was found to be replaced by collaterals with patent splenoportal confluence, splenic and superior mesenteric veins. Computed tomog-
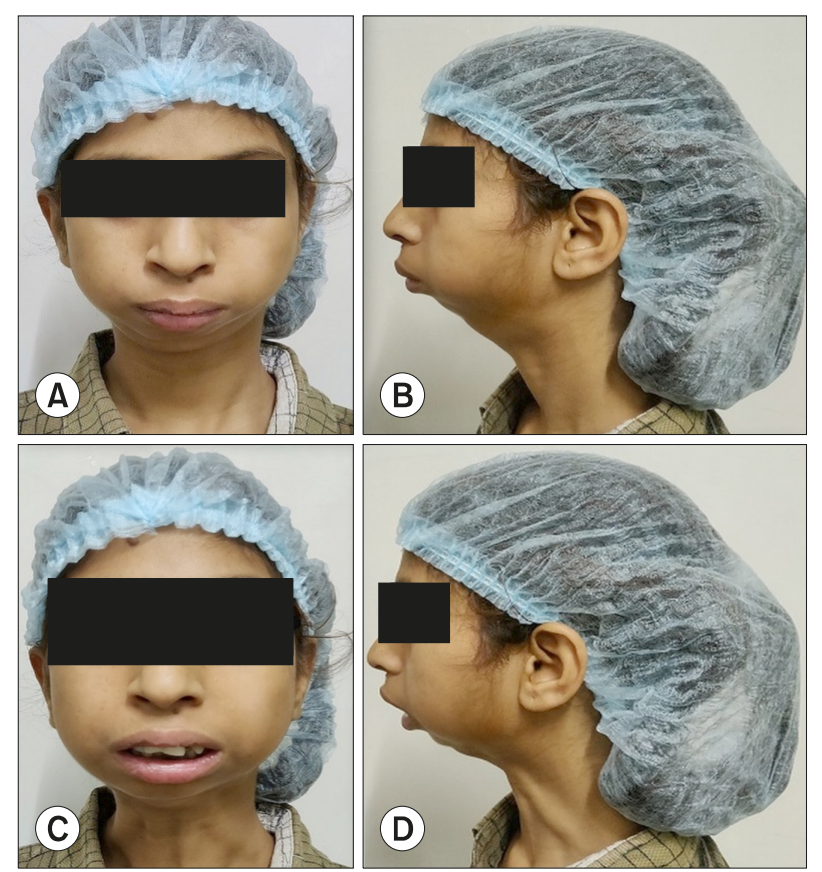

Fig. 1. (A and B) shows patient with micrognathia with jaws closed. (C and D) show minimal mouth opening. raphy of face showed mandibular hypoplasia with bilateral TMJ ankylosis (Fig. 2).

With the above mentioned clinical, laboratory and radiological findings, a diagnosis of recurrent esophageal variceal bleed due to EHPVO with associated TMJ ankylosis was made and was planned for proximal splenorenal shunt with tube gastrostomy for feeding followed by release of TMJ ankylosis in staged procedure. Nasotracheal intubation was done. Intra operatively left lateral lobe of liver was found to be atrophic and spleen was moderately enlarged with focal areas of splenic infarct and perisplenitis. Multiple collaterals were present around spleen and retroperitoneum. Splenic vein was dilated to $1.5 \mathrm{~cm}$ which was mobilized till spleno-portal junction and end to side splenorenal shunt (Fig. 3) was performed with Prolene 6-0 in continuous fashion (anastomotic size of $15 \mathrm{~mm}$ ). Tube gastrostomy was made with $22 \mathrm{~F}$ Foley catheter in anterior wall of distal stomach for feeding which was planned
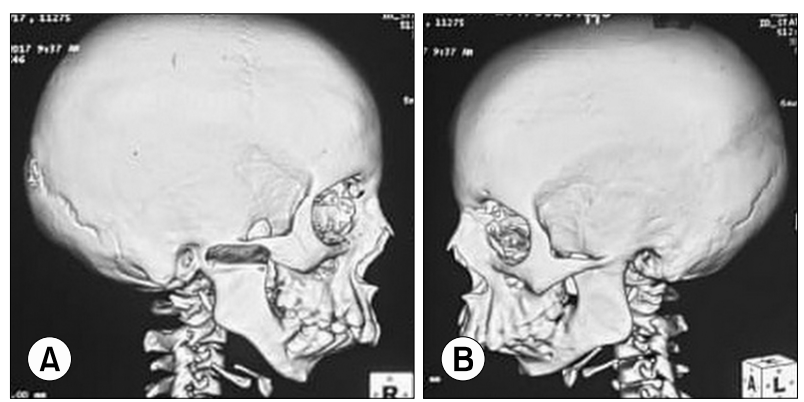

Fig. 2. (A, B) Right and left lateral views of the skull respectively depicting the bonyfusion of the temporomandibular joint with hypoplasia of the mandible.

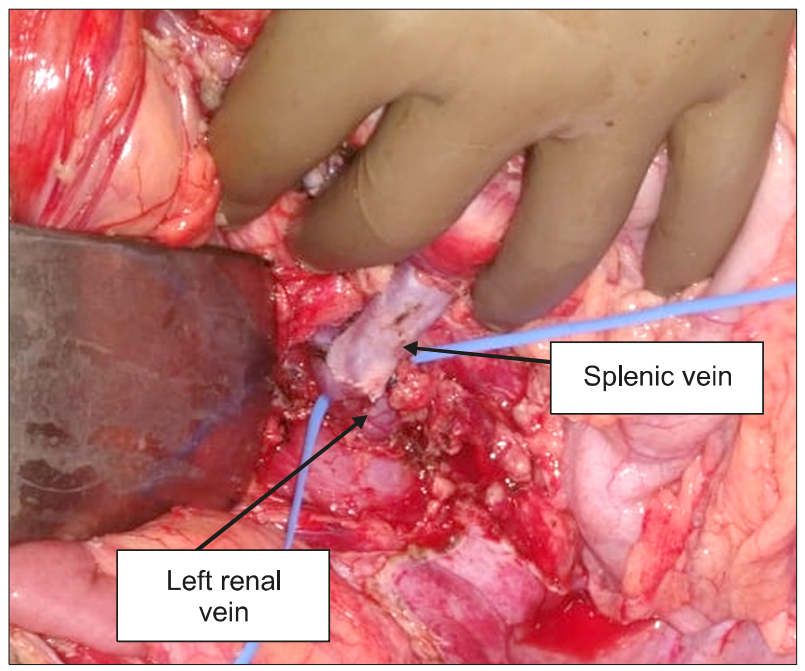

Fig. 3. shows end to side proximal splenorenal shunt. 
Table 1. Reported case report of EHPVO with TMJ ankylosis

\begin{tabular}{|c|c|c|c|c|c|}
\hline Reference & $\begin{array}{l}\text { Total } \\
\text { case }\end{array}$ & $\begin{array}{l}\text { Age } \\
\text { (year)/ } \\
\text { sex }\end{array}$ & Hypercoagulable status & Platelets count & Surgery \\
\hline Sahoo et al. ${ }^{4}$ (2007) & 1 & $8 / \mathrm{M}$ & NA & $86,000 / \mathrm{mm}^{3}$ & $\begin{array}{l}\text { Right TMJ ankylosis release with } \\
\text { interpositional arthroplasty }\end{array}$ \\
\hline 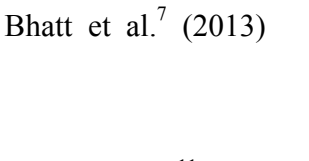 & 4 & $\begin{array}{l}30 / \mathrm{M} \\
29 / \mathrm{F} \\
10 / \mathrm{F} \\
7 / \mathrm{M}\end{array}$ & $\begin{array}{l}2 \text { out of } 4 \text { patients had } \\
\text { proven protein } \mathrm{C} \text { deficiency }\end{array}$ & & 2 (details NA) \\
\hline Akshat et al. ${ }^{11}$ (2017) & 1 & 9/M & NA & $72,000 / \mathrm{mm}^{3}$ & Proximal splenorenal shunt \\
\hline Present case & 1 & $14 / \mathrm{F}$ & $\begin{array}{l}\text { Protein C } 68.3 \mathrm{IU} / \mathrm{dl} \text {, } \\
\text { (normal range } 72.3-155.1 \text { ) } \\
\text { Protein S } 57.3 \mathrm{U} / \mathrm{dl} \text {, } \\
\text { (normal range } 61.4-130.7 \text { ) }\end{array}$ & $61,000 / \mathrm{mm}^{3}$ & Proximal splenorenal shunt \\
\hline
\end{tabular}

to be kept for longer duration which might aid future endoscopic interventions in case of failure of TMJ ankylosis release.

Post-operative period was uneventful. She was started on intravenous heparin which was overlapped with tablet Acitrom $^{\circledR}$ in view of protein $\mathrm{C}$ and $\mathrm{S}$ deficiency. On postoperative day 5, Doppler study was done which showed patent shunt with good flow. She was discharged on postoperative day 7 with an INR of 1.9. After 8 month of surgery she is doing well, and her shunt is patent.

\section{DISCUSSION}

Both EHPVO and TMJ ankylosis are significant health problems in developing countries, usually seen in poor socioeconomic patients. ${ }^{2,3}$ Recently association of EHPVO and temporomandibular joint (TMJ) ankylosis has also been reported (Table 1). The etiologies of TMJ ankylosis include trauma, infection, arthritis, and surgery with majority of the reports agreeing on trauma being the most common etiology of TMJ ankylosis. It remains unclear, why only a small percentage (0.4-2\%) of condylar fractures develop ankylosis. ${ }^{5,6}$

Bhatt et al. ${ }^{7}$ recently reported 4 cases with bilateral TMJ ankylosis and extrahepatic portal venous obstruction (EHPVO), two of them had protein $\mathrm{C}$ deficiency. They postulated that protein $\mathrm{C}$ deficiency may lead to delay in lysis of the big fibrin network that is formed in and around the exposed medullary spaces following a condylar fracture leading to TMJ ankylosis. While hypercoagulability in protein $\mathrm{C}$ deficiency causes portal vein thrombo- sis and its sequalae EHPVO and variceal bleed. We also had a similar case that had TMJ ankylosis and EHPVO with variceal bleed. Though there was no history of trauma in our patient but had history of ear infections after which she gradually developed restricted mouth opening as a sequalae of septic arthritis eventually leading to TMJ ankylosis. ${ }^{8}$

Apart from a possible common etiopathological factor, an EHPVO patient presenting with TMJ ankylosis poses a great challenge in the management of upper GI bleed, as endoscopic management is not feasible due to lack of adequate mouth opening. Corrective surgery for TMJ ankylosis prior to variceal management may be disastrous due to underlying thrombocytopenia in these patients.

Proximal spleno-renal shunt (PSRS) surgery for variceal bleed management and correction of hypersplenism and may help in future corrective surgery for TMJ ankylosis. But surgical management is also very challenging in these patients because of difficult airway, due to inadequate mouth opening, near total trismus, overcrowding of soft tissues, associated mandibular/maxillary hypoplasia as well as altered position of larynx may be due to facial asymmetry. These patients also commonly have obstructed sleep apnea which further complicates awake intubation in these patients. In EHPVO with portal hypertension and bleeding varices, increased risk of aspiration and bleeding during airway management due to splenomegaly may further add to the problem of airway management. ${ }^{9}$ Techniques of airway management in these patients are blind nasal intubation, retrograde intubation over wire, fiberoptic -guided intubation or tracheotomy. Fiberoptic intubation is 
the ideal technique to secure the airway but during this procedure, standby tracheostomy or other equipment to secure surgical airway should be kept ready. ${ }^{10,11}$ In our patient blind nasal intubation done by experienced anesthetist was successful with fiberoptic intubation and tracheostomy was kept as a standby. She underwent proximal splenorenal shunt and her post-operative period was uneventful.

\section{CONCLUSION}

Children who develop TMJ ankylosis secondary to trauma or infection should also be evaluated for hypercoagulable disorders and its sequalae like EHPVO. Though a rare association it might give a valuable insight into the pathophysiology of TMJ ankylosis.

\section{ACKNOWLEDGEMENTS}

None.

\section{CONFLICT OF INTEREST}

None.

\section{ORCID}

Kailash Chand Kurdia:

https://orcid.org/0000-0002-9600-7981

Ambuj Aggarwal: https://orcid.org/0000-0002-5692-892X

Cherring Tandup: https://orcid.org/0000-0003-0230-7949

Divya Dahiya: https://orcid.org/0000-0002-0237-8459

Subrata Podder: https://orcid.org/0000-0002-5534-5431

Arunanshu Behera: https://orcid.org/0000-0003-0954-0372

\section{AUTHOR CONTRIBUTIONS}

Conceptualization: KCK, AB. Data curation: AA. Writing original draft: KCK, AA. Writing - review \& editing: CT, DD, SP.

\section{REFERENCES}

1. Khanna R, Sarin SK. Idiopathic portal hypertension and extrahepatic portal venous obstruction. Hepatol Int 2018;12(Suppl 1): 148-167.

2. Sarin SK, Agarwal SR. Extrahepatic portal vein obstruction. Semin Liver Dis 2002;22:43-58.

3. Roychoudhury A, Parkash H, Trikha A. Functional restoration by gap arthroplasty in temporomandibular joint ankylosis: a report of 50 cases. Oral Surg Oral Med Oral Pathol Oral Radiol Endod 1999;87:166-169.

4. Sahoo T, Patil Y, Patel R, Dewoolkar L. Anaesthetic management of a child with temporomandibular joint ankylosis with extrahepatic portal vein obstruction for ankylosis release. Internet J Anesthesiol 2007;16:1-5.

5. Laskin DM. Role of the meniscus in the etiology of posttraumatic temporomandibular joint ankylosis. Int J Oral Surg 1978; 7:340-345.

6. Hong M. [TMJ reconstruction of the intracapsular condylar vertical fracture]. Zhonghua Kou Qiang Yi Xue Za Zhi 1990;25:346348, 383. Chinese.

7. Bhatt K, Roychoudhury A, Balakrishnan P. Temporomandibular joint ankylosis: is hypercoagulable state of blood a predisposing factor? Med Hypotheses 2013;81:561-563.

8. Regev E, Koplewitz BZ, Nitzan DW, Bar-Ziv J. Ankylosis of the temporomandibular joint as a sequela of septic arthritis and neonatal sepsis. Pediatr Infect Dis J 2003;22:99-101.

9. Dasgupta D. Endotracheal intubation in bilateral temporomandibular joint ankylosis. Indian J Anaesth 1987;35:367-373.

10. Berry FA. Difficult intubation In: Berry FA, ed. Anesthetic management of difficult and routine pediatric patients. 2nd ed. New York: Churchill Livingstone, 1990:373-382.

11. Akshat S, Jain S, Khanna P, Batra RK. Airway management of a paediatric patient with temporomandibular joint ankylosis with extra hepatic portal vein obstruction, splenomegaly, hypersplenism, and obstructive sleep apnoea for shunt surgery: a unique challenge. Indian J Anaesth 2017;61:943-944. 